\title{
Menstrual Hygiene: Knowledge and Practice among Adolescent School Girls In rural areas of West Bengal
}

\author{
Dr Dipanwita Pandit ${ }^{1,}$ Dr Prasanta Kumar Bhattacharyya ${ }^{2,}$ \\ Dr Raja Bhattacharya ${ }^{3}$ \\ ${ }^{1}$ Department of Community Medicine, Medical College, Kolkata, India \\ ${ }^{2}$ Department of Plastic Surgery, KPC Medical College, Kolkata, India \\ ${ }^{3}$ Department of General Medicine, Medical College, Kolkata, India
}

\begin{abstract}
Menstruation is generally considered as unclean in the Indian society. Isolation of the menstruating girls and restrictions being imposed on them in the family, have reinforced a negative attitude towards this phenomenon. There is a substantial lacuna in the knowledge about menstruation among adolescent girls. Although menstruation is a natural process, it is linked with several misconceptions and practices. Hygiene-related practices of women during menstruation are of considerable importance, as it has a health impact in terms of increased vulnerability to reproductive tract infections (RTI). Good hygienic practices such as the use of sanitary pads and adequate washing of the genital area are essential during menstruation. Menstrual hygiene and management will directly contribute to the Millennium Development Goal (MDG)-2 on universal education and $M D G-3$ on gender equality and women empowerment.
\end{abstract}

Key Words: Adolescent girls, menstrual hygiene, Millennium Development Goal

\section{Introduction}

Adolescence in girls has been recognized as a special period which signifies the transition from girlhood to womanhood. Menstruation is generally considered as unclean in the Indian society. Isolation of the menstruating girls and restrictions being imposed on them in the family, have reinforced a negative attitude towards this phenomenon. ${ }^{1}$ Several studies have reported restrictions and belief in specified taboos at menarche and menstruation. ${ }^{2}$ There is a substantial lacuna in the knowledge about menstruation among adolescent girls. Social prohibitions and the negative attitude of parents in discussing the related issues openly, have blocked the access of adolescent girls to the right kind of information, especially in the rural and tribal communities. Most of the adolescent girls had incomplete and inaccurate information about the menstrual physiology and hygiene. Good hygienic practices such as the use of sanitary pads and adequate washing of the genital area are essential during menstruation. Women and girls of the reproductive age need access to clean and soft, absorbent sanitary products which can in the long run, protect their health. Menstrual hygiene and management will directly contribute to (MDG)-2 on universal education, MDG-3 on gender equality and women empowerment. ${ }^{3}$ However, the attention on this issue is far from sufficient and even the literature on gender mainstreaming in the sanitary section is silent on the issue of menstrual management. ${ }^{4}$ A key priority for women and girls is to have the necessary knowledge, facilities and the cultural environment to manage menstruation hygienically and with dignity. The data about their level of knowledge and the practices which are followed by them with respect to menstruation are beneficial for planning a program for improving the awareness level with respect to their life processes and promoting their quality of life. Hence, the present cross sectional study was carried out with the objectives:

1. To assess the knowledge and the practices of menstrual hygiene among rural school going adolescent girls.

2. To assess the restrictions which were practised by adolescent school girls during menstruation.

\section{Methodology}

An observational cross sectional study was performed between October-2012 to September-2013 among adolescent girls attending two girls' school in Tarakeswar Block, Hooghly District which is rural field practice area of Department of Community Medicine, Medical College,Kolkata. From 4 girls' schools in Tarakeswar Block,2 schools were randomly selected. After taking Administrative approval from respective authorities and according to the schedule of the examination, only class VIII, IX, X was selected. All the students who were present on the day of survey were included. All girls of class VIII, IX \& X of those two schools were interviewed by using predesigned- pretested semi structured-schedule and examined. Students were included in the study after taking informed verbal consent. One day was fixed in each school to maintain uniformity of the questionnaire and to prevent percolation of information. Subsequently many other visits were made for examination of the girls of different classes. Total 464 students were interviewed. Due to incompleteness of response by 29 students, finally 435 schedules were used for analysis. Data was tabulated in 
Microsoft Excel 2010 spread sheet \& analysed by appropriate statistical methods in SPSS 16 software. Discrete data was analysed using Pearson's Chi-square test for normal distribution, values $<0.05$ were considered significant.

\section{Results}

In the study it was found that all the participants were unmarried females and students of classes VIII, IX, X.Largest proportion of the students was in the age group 10-14 years i.e. 262(60.22\%), while the least proportion was in the age group 18-19years i.e. $6(1.39 \%)$. Mean age of the students was $14.36 \pm 1.28$ years with a range from13-18 years. 140(32.18\%) students were in class VIII while 166(38.17\%) and 129(29.65\%) studied in class IX and X respectively. Most i.e. 351(80.68\%) of the students belonged to Hindu religion while 84(19.32\%) students belonged to Muslim community. More than $90 \%$ of the girls belonged to lower middle and poor socioeconomic status i.e. Class IV \& V of Prasad' Scale ( $40.45 \%$ and $51.72 \%$ respectively). Most $(69.43 \%)$ of the students belonged to nuclear families. Most of girls (39.08\%) had only one sibling while $29.19 \%$ girls had no sibling. 107(24.59\%) students' fathers had their own business and 93(21.37\%) were in service. Largest proportion of students' mothers were found to be educated up to middle school i.e.143(32.89\%), followed by primary $111(25.53 \%)$, secondary $102(23.44 \%)$, higher secondary $52(11.95 \%)$, graduate $18(4.13 \%)$, while $9(2.06 \%)$ mothers were illiterate. All students had attained menarche. Mean age of menarche was $11.51 \pm 1.02$ years and mean duration of menstruation was $5.04 \pm 0.88$ days. For all participants, mean duration of menstrual cycle was $28.65 \pm 1.01$ days.Among 189 girls, $127(67.19 \%)$ reported pain, $90(47.61 \%)$ reported headache and $74(39.15 \%)$ girls reported irritability as PMS. Pain abdomen was the most commonly associated symptom among $88.96 \%$ of students, followed by weakness $(26.43 \%)$ and excessive bleeding $(22.06 \%)$. Itching around genitalia $(12.87 \%)$, headache $(7.58 \%)$, nausea/vomiting $(6.89 \%)$ and breast pain $(4.36 \%)$ were the other associated symptoms. Regarding knowledge and perception regarding menstruation correct knowledge was found among $370(85.05 \%)$ girls, while $15.04 \%$ ascribed it to either disease or a curse of God. 315(72.41\%) girls had knowledge on menstruation before menarche. Among them, 199(63.17\%) girls reported that they had got knowledge on menstruation from their mother and $25.07 \%$ girls said that teacher was the informant. $178(40.94 \%)$ girls had the correct knowledge that uterus was the source of menstrual blood, while others marked urinary bladder $(8.27 \%)$,vagina( $45.74 \%)$ or abdomen(5.05\%) to be the sources. $222(51.03 \%)$ girls knew that pregnancy is the cause of missed period and $20(4.59 \%)$ girls did not know the cause. Regarding practice of the study population during menstruation312 $(71.72 \%)$ girls used sanitary napkins while $23(5.28 \%)$ girls used both sanitary napkin and cloth as absorbent. Among 23 students of upper middle socio economic status, $12(52.17 \%)$ were used sanitary napkins and 11(47.83\%) were used other cloths while among 225 students of poor socio economic status, $75(33.34 \%)$ used sanitary napkins and $150((66.66 \%)$ students were used other cloths and the relationship found to be statistically significant $(\mathrm{P}<0.01)$. 393(90.36\%) girls changed absorbent two to four times a day while 29(6.66\%) students once changed their absorbents and 195 (44.85\%) students changed their absorbents at night. It has been seen that 197 (45.28\%) students changed their absorbents at school. Both schools had separate toilet with running water facilities. 93(40.54\%) girls stated that they dried their absorbents inside the home without sunlight while 19(8.33\%) girls dried absorbents outside home without sunlight. 52\% students stored their absorbents in a bag in the bathroom. Dustbin was the most commonly used place of disposal of used absorbent (46.20\%) but 27(6.19\%) students threw used pad on the roadside. Among 408 students, $218(53.44 \%)$ students used soap and water for cleaning of genitalia during menstruation.

Most $(71.26 \%)$ of the participants refrained from religious activities, followed by absenteeism from school $(17.93 \%)$ and playing $(17.01 \%)$.

\section{Discussion}

In the present study, an effort has been made to find out the perception and practices during menstruation. There are Individual differences in the timing of menarche which is influenced by both heredity and environment i.e. physical and psychosocial components. Potential physical influences, such as weight, nutrition and exercise and potential psychosocial factors, such as family environment, child behavioural problems and stressful life events could play an important role. These factors may vary with different study settings. In the present study, all students had attained menarche. Mean age of menarche was $11.51 \pm 1.024$ years and mean duration of menstruation was $5.04 \pm 0.88$ days. Mean duration of menstrual cycle was $28.65 \pm 1.01$ days for all participants. A striking range of variation exists in the mean ages of menarche and it is declining. Majority of girls achieved menarche between the age 12 and 14 years. The percentage distribution indicated that more number $(69.43 \%)$ of girls from nuclear family attained menarche at earlier age as compare to joint families. The possible reason may be due to better nutrition, proper care and better education of mother. Rapid urbanisation may be another cause. It has been found that the girls having puberty earlier or later, the pattern of menstruation is similar. In the present study reveals that the mean interval between two regular cycles was 28.96 days and the mean duration of menstrual flow was 4.19 days. These results are in conformity with study by 
Singh et al. ${ }^{5}$ found the mean interval between two regular cycles was 29.3 days and duration of menstrual flow was 5 days. Menstruation is associated with health problems such as headache, body pain abdomen, and vomiting, fainting and menstrual problems such as menorrhagia, amenorrhea, dysmenorrhoea, premenstrual tension and leucorrhoea.In the present study, among189 girls, 127(67.19\%) reported pain, 90(47.61\%) reported headache and 74(39.15\%) girls reported irritability as pre- menstrual symptoms (PMS).Pain abdomen was the most commonly associated symptom among $88.96 \%$ of students, followed by weakness $(26.43 \%)$ and excessive bleeding (22.06\%).Itching around genitalia (12.87\%), headache $(7.58 \%)$, nausea/vomiting $(6.89 \%)$ and breast pain $(4.36 \%)$ were the other associated symptoms. Accordingly the results regarding pre-menstrual symptoms revealed that majority $(67.19 \%)$ of girls reported about abdominal pain followed by headache $(47.61 \%)$ and irritability (39.15\%) prior to menstruation. The regional difference was observed in the above mention pattern of problems. Where in Dharwad, more number (42.85\%) of girls reported abdominal pain followed by irritability and back ache $(22.44 \& 18.36 \%$ respectively). While, more number $(32.60 \%)$ of Khurda girls were reported about irritability followed by abdominal pain $(23.91 \%)$. This is may be because of lifestyle, food habit and stressful situation. Regarding problems during menstrual the results indicated that more $(88.96 \%)$ number of girls reported about pain abdomen followed by weakness $(26.43 \%)$ and excessive bleeding (22.06\%). Further similar problems were reported by Dharwad and Khurda girls. Earlier studies conducted by, Poureslami et.al. ${ }^{6}$ Avasarala et.al. ${ }^{7}$, Nair et.al. ${ }^{8}$ and Sharma et.al. ${ }^{9}$ also found that more number of adolescents reported about menstrual problem such as pain abdomen, fatigue, muscle stiffness, restlessness and irritability. The menstrual problem reported by girls in the study might be attributed to factors such as poor nutritional status, psychological stress, anxiety, fear, excessive menstrual flow, irregular or infrequent periods being overweight, and being underweight or mal nourished. About sanitary practices followed by girls during menstrual periods, regarding the type of sanitary parts used by girls in present study it was found that $71.72 \%$ girls used sanitary napkin and $28.28 \%$ were using cloths as absorbents.

\begin{tabular}{|c|c|c|c|}
\hline Author & $\begin{array}{l}\text { Year of } \\
\text { Publication }\end{array}$ & Place & $\begin{array}{l}\text { Practice during } \\
\text { Menstruation }\end{array}$ \\
\hline Dasgupta A, Sarkar M. ${ }^{10}$ & 2008 & $\begin{array}{l}\text { West Bengal } \\
\text { Singur }\end{array}$ & $\begin{array}{l}11.25 \% \text { girls used sanitary napkin } \\
42.5 \% \text { used old cloth, } \\
6.25 \% \text { new cloth }\end{array}$ \\
\hline Sharma P et.al. ${ }^{11}$ & 2008 & Urban South India & $\begin{array}{l}68.9 \% \text { girls used sanitary napkin } \\
21.04 \% \text { used old cloth }\end{array}$ \\
\hline Thakre et.al ${ }^{12}$ & 2011 & Maharashtra & $\begin{array}{l}30.82 \% \text { girls used sanitary napkin } \\
62.33 \% \text { used old cloth and } \\
6.85 \% \text { used new cloth }\end{array}$ \\
\hline Goel MK et.al. ${ }^{13}$ & 2011 & rural Maharashtra & $\begin{array}{l}15.67 \% \text { girls used sanitary napkin } \\
68.34 \% \text { used old cloth }\end{array}$ \\
\hline Ruchi Juyal. et. al. ${ }^{14}$ & 2012 & Uttarakhand & $\begin{array}{l}48.1 \text { girls used sanitary napkin } \\
30 \% \text { used new cloth }\end{array}$ \\
\hline Present Study & 2013 & $\begin{array}{l}\text { Tarakeswar } \\
\text { West Bengal }\end{array}$ & $\begin{array}{l}\text { 71.72\% girls used sanitary napkin } \\
14.25 \% \text { used old cloth } \\
\text { 8.75\% used new cloth } \\
5.28 \% \text { used both napkin\& cloth }\end{array}$ \\
\hline
\end{tabular}

The number of girls using sanitary napkins was found to be much higher than studies in rural Maharashtra(15.67\%) and urban South India (68.9\%). ${ }^{11,13}$ Difference in use of sanitary napkin is possibly due to number of factors like availability, accessibility, cost, exposure to media, customs, storage and disposal issues. Regarding disposal of pads, majority (46.20\%) of girls disposed them in dustbin but $6.19 \%$ girls threw used pad on the roadside. Most of the girls $(90.36 \%)$ practiced changing their pads 2-4 times a day and $44.85 \%$ girls changed their pads at night which compares well with the study in South India. ${ }^{15}$ Practice of changing absorbent while in school was practiced by $45.28 \%$ students. This observation was similar to that by Begum et.al. ${ }^{15}$ Soap and water were used as cleaning agents by $53.44 \%$ girls which was similar to the findings by Mudey et. al.in Wardha District but differed much from the study of Dasgupta and Sarkar. ${ }^{10,16}$ Taboos and superstitions regarding menstruation are prevalent in rural areas, as maximum restriction $(71.26 \%)$ was found on religious activities. Similar finding was reported on study done by DasguptaA.et.al. ${ }^{10}$ and Goel MK et.al ${ }^{13}$ in rural Bengal and rural Maharashtra. Such similar findings in different study settings reflect the negative attitude to menstruation.

\section{Conclusion}

This study has highlighted the need of adolescent girls to have accurate and adequate information about menstruation and its appropriate management. Formal as well as informal channels of communication such as 
mothers, sisters and friends, need to be emphasized for the delivery of such information. In view of the vital role of the mothers, it is very important that the mother be armed with the correct and appropriate information on reproductive health, so that she can give this knowledge to her growing girl child. It is also essential for the teachers, who may not have the necessary skills to impart reproductive health education, including menstrual hygiene to their students. There is a strong need to address issues like the restrictions which are imposed on or practiced by the adolescent school girls. The reproductive health implications of menstruation and its management, and its effect on the quality of life which permeates school and other social activities are many for the adolescent school girls. These invariably call for all the stakeholders-family, school community, civil society, and service providers to entrench correct menstrual perceptions and to enable proper hygiene practices amongst this segment of the population). Awareness regarding the need for information on healthy menstrual practices is very important. It is essential to design a mechanism to address and for the access of healthy menstrual practices.

\section{Acknowledgements}

We are thankful to BMOH, Lady counsellor and students for their cooperation and support.

\section{Tables and Charts}

Figure 1: Pie diagram showing distribution of the study population according to type of absorbents used

$(n=435)$

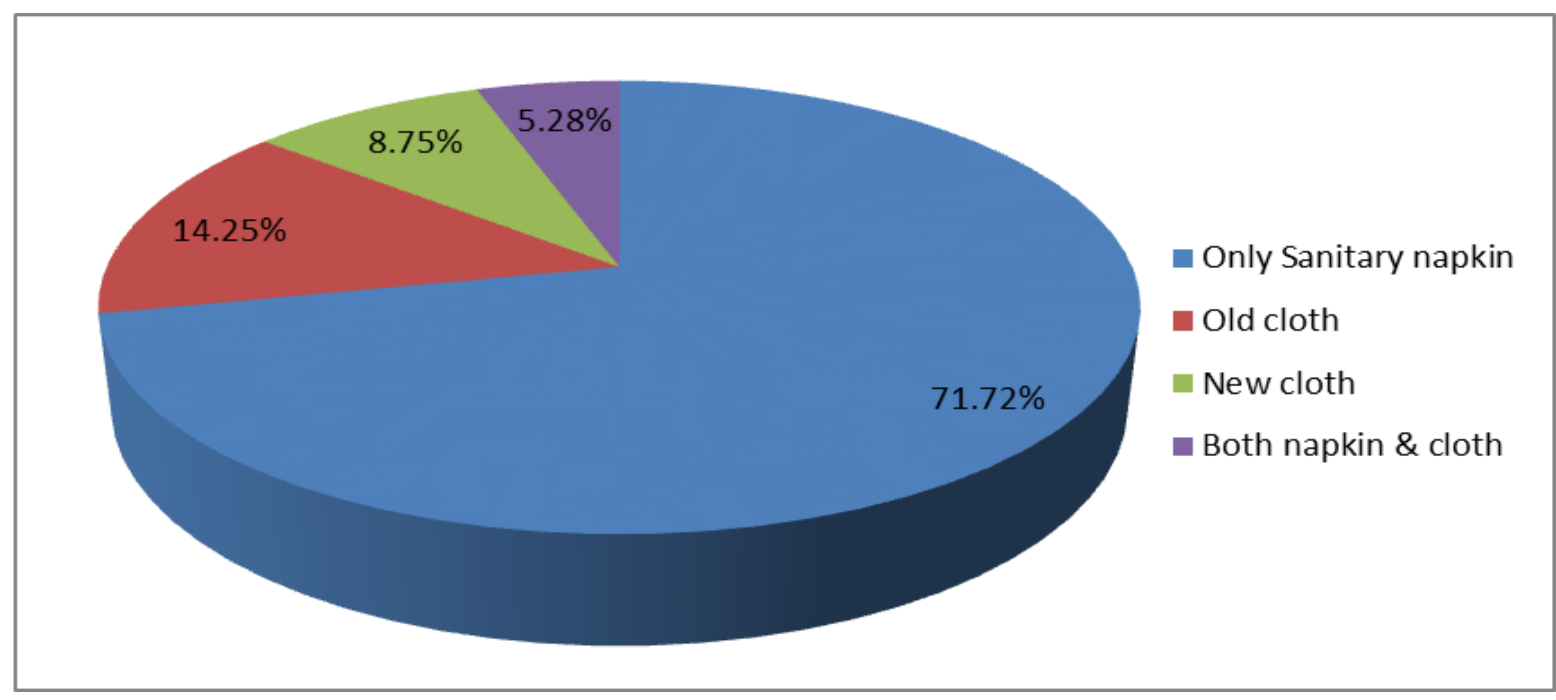

Table1: Socio demographic profile of the study population

\begin{tabular}{|c|c|c|c|c|c|c|c|}
\hline Socio demographic profile & 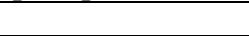 & & Number & & & Percentage & \\
\hline $\begin{array}{l}\text { Religion } \\
\text { Muslim }\end{array}$ & Hindu & 351 & & 84 & & 19.32 & 80.68 \\
\hline $\begin{array}{l}\text { Family } \\
\text { Joint }\end{array}$ & Nuclear & & 133 & 302 & & 30.57 & 69.43 \\
\hline 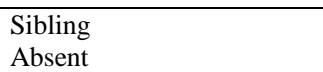 & Present & & 127 & 308 & & 29.19 & 70.81 \\
\hline $\begin{array}{l}\text { Socio Economic Status } \\
\text { Upper Middle(5118-8529) } \\
\text { Middle(2559-5117) } \\
\text { Poor }(853-2558) \\
\text { BPL }(<853)\end{array}$ & Lower & 225 & $\begin{array}{c}23 \\
176\end{array}$ & 11 & & $\begin{array}{c}5.31 \\
40.45 \\
51.72 \\
2.52\end{array}$ & \\
\hline $\begin{array}{l}\text { Occupation of Father } \\
\text { Shopkeeper } \\
\text { Service } \\
\text { employed }\end{array}$ & $\begin{array}{c}\text { Farmer } \\
\text { Business } \\
\text { Self- } \\
\text { Others }\end{array}$ & $\begin{array}{l}55 \\
107\end{array}$ & $\begin{array}{l}41 \\
91\end{array}$ & $\begin{array}{l}48 \\
93\end{array}$ & $\begin{array}{l}12.64 \\
24.59 \\
9.42\end{array}$ & & $\begin{array}{l}11.07 \\
21.37 \\
20.91\end{array}$ \\
\hline $\begin{array}{l}\text { Education of Mother } \\
\text { Primary } \\
\text { School } \\
\text { Higher Secondary } \\
\text { Graduate }\end{array}$ & $\begin{array}{r}\text { Illiterate } \\
\text { Middle } \\
\text { Secondary }\end{array}$ & $\begin{array}{l}9 \\
143 \\
52\end{array}$ & & $\begin{array}{l}111 \\
102 \\
18\end{array}$ & $\begin{array}{l}2.06 \\
32.89 \\
11.95\end{array}$ & & $\begin{array}{c}25.53 \\
23.44 \\
4.13\end{array}$ \\
\hline
\end{tabular}


Table2: Knowledge and perception of the study population regarding menstruation $(n=435)$

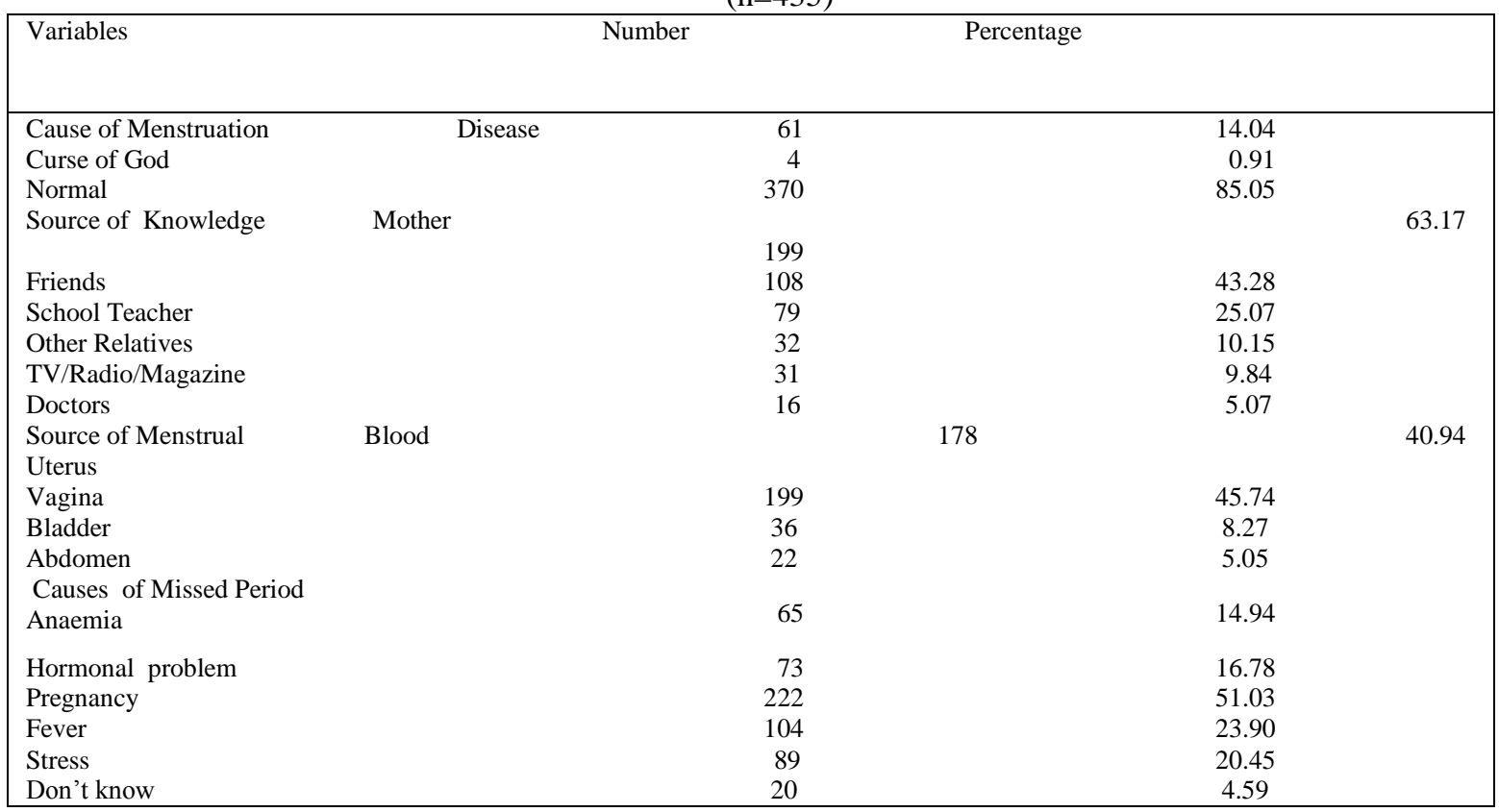

Table3: Practice of the study population during menstruation $(n=435)$

\begin{tabular}{|c|c|c|c|}
\hline Variables & Number & Percentage & \\
\hline $\begin{array}{l}\text { Absorbents Changed } \\
\text { (Number of Times/day) }\end{array}$ & 29 & & 6.66 \\
\hline $2-4$ & 393 & 90.36 & \\
\hline $5-6$ & 13 & 2.98 & \\
\hline $\begin{array}{l}\text { Change absorbents in school } \\
\text { Yes }\end{array}$ & 197 & 45.28 & \\
\hline No & 238 & 54.72 & \\
\hline $\begin{array}{l}\text { Absorbents Dried } \\
\text { Inside home with sunlight }\end{array}$ & 82 & 35.56 & \\
\hline Inside home without sunlight & 93 & 40.54 & \\
\hline Outside home with sunlight & 36 & 15.57 & \\
\hline Outside home without sunlight & 19 & 8.33 & \\
\hline $\begin{array}{l}\text { Disposal of absorbent } \quad \text { Domestic } \\
\text { refuse }\end{array}$ & 114 & 26.25 & \\
\hline Burning & 2 & 0.45 & \\
\hline Roadside & 27 & 6.19 & \\
\hline Dustbin & 201 & 46.20 & \\
\hline Burial & 91 & 20.91 & \\
\hline
\end{tabular}

\section{References}

[1] Dhingra R, Kumar A. Knowledge and practices related to menstruation among tribal (Gujjar) adolescent girls. Etho-Med 2009; 3(1):43 48 .

[2] Singh AJ. The place of menstruation in the reproductive lives of women of rural north India. Indian Journal of Community Medicine 2006; 31(1):10-14.

[3] Ten V TA. Menstrual Hygiene: A neglected condition for the achievementof the Millennium Development Goals. Europe External policy Advisors, 2007.

[4] Water Aid: Is Menstrual Hygiene and Management an issue for Adolescent Girls? Water Aid in South Asia Publication; 2009

[5] Singh, G. M. P., 1986, Onset of menarche in girls of Ludhiana. Indian Paedriatritian, 23: 263-265

[6]. Poureslami, M. and Ashtiani, F. O., 2002, Attitudes of Female Adolescents about Dysmenorrhea and Menstrual Hygiene in Tehran Suburbs. Arch Iranian Med, 5 (4): 219-224.

[7] Avasarala, A. K. and Panchangam, S., 2008, Dysmenorrhoea in Different Settings : Are the Rural and Urban Adolescent Girls Perceiving and Managing the Dysmenorrhoea Problem Differently? Indian Journal of Community Medicine, 33 (4): $246-249$.

[8] Nair, P., Vijay, L. G. And Kanan, A. T., 2007, Awareness and Practices of Menstruation and Pubertal Changes amongst Unmarried Female Adolescents in Rural Area of East Delhi. Indian Journal of Community Medicine, 32 (2): 156.

[9] Sharma, P., Malhotra, C., Taneja, D. K. and Saha, R., 2008, Problems related to menstruation amongst adolescent girls. Indian Journal of Paediatrics, 75: 125-129

[10] Dasgupta A, Sarkar M. Menstrual Hygiene: How Hygienic is the Adolescent Girl? Indian J Community Med 2008 Apr;33 (2):77-80 
[11] Sharma S.et.al. Health Awareness of Rural Adolescent Girls: An Intervention Study J Soc Sci, 21(2): 99-104 (2009)

[12] Thakre.et.al.Menstrual Hygiene: Knowledge and Practice among Adolescent School Girls of Saoner, Nagpur DistrictJournal of Clinical and Diagnostic Research. 2011 October, Vol-5(5): 1027-1033.

[13] Goel MK, Mittal K. Psycho-social Behaviour of Urban Indian Adolescent Girls during menstruation. Australasian Medical Journal 2011;4:49-52.

[14] Ruchi Juyal. PRACTICES OF MENSTRUAL HYGIENE AMONG ADOLESCENT GIRLS IN A DISTRICT OF UTTARAKHANDhttp://iapsmupuk.org/journal/index.php/ijchVol 24, No 2 (2012)

[15] Omidvar S, Begum K. Factors influencing hygienic practices during menses among girls from south India- A cross sectional study. International Journal of Collaborative Research on Internal Medicine \& Public Health 2010 Dec;2(12):411-23.

[16] Mudey AB, Kesharwani N, Mudey GA, Goyal RC. A Cross-sectional Study on Awareness Regarding Safe and Hygienic Practices amongst School Going Adolescent Girls in Rural Area of Wardha District, India. Global journal Health Science 2010 Oct;2(2):22531. 